\section{Relationship between chronic diseases and diet in older persons in nursing homes}

\author{
Melahat Kizil,, ${ }^{1}$ Kamile Nazan Turhan, ${ }^{2}$ \\ Ramazan Kizil, ${ }^{3}$ Nursun Ustunkarli ${ }^{1}$ \\ ${ }^{1}$ Izmir University of Economics, \\ Vocational School of Health Services; \\ ${ }^{2}$ Izmir University of Economics, Faculty \\ of Engineering, Food Engineering; \\ ${ }^{3}$ Dokuz Eylül University, Faculty of \\ Medicine, Physical Therapy and \\ Rehabilitation, Izmir, Turkey
}

\section{Abstract}

This study aimed to determine the relationship between chronic diseases and nutrition in the older adults in a nursing home.

In 2014 and 2019, we investigated older people aged 60 years and over living in a nursing home in Izmir and who agreed to participate and could perform self-care. A 26-item questionnaire that focuses on sociodemographic, socioeconomic and chronic disease characteristics, and the Turkish version of Mini Nutritional Assessment Test-Short Form were applied using the face-to-face method.

In $2014,68.9 \%$ of the older had no malnutrition risk, $23 \%$ had malnutrition risk, and $8.1 \%$ had malnutrition. The women had a higher malnutrition risk and actual malnutrition than men $(\mathrm{P}<0.05)$. Malnutrition was most common in $75-84$ years of age. In 2019 , $41.6 \%$ of the older had malnutrition risk, whereas $7.8 \%$ had actual malnutrition. No difference was found between malnutrition and malnutrition risk, between women and men and between age and sex $(\mathrm{P}>0.05)$. At both times, malnutrition risk increased in those with chronic disease $(\mathrm{P}<0.05)$. At least one chronic disease (high blood pressure, heart disease, diabetes, etc.) was found in $67.6 \%$ of the older. Meanwhile, $70.1 \%$ had been previously hospitalized for some reason.

Malnutrition risk increases with old age. An adequate and well-balanced diet is important for protecting health and increasing longevity and quality of life in old age. Older people and nursing home employees need to be trained on the relationship and risks of chronic disease and malnutrition.

\section{Introduction}

The older population is increasing rapidly across the world. Consequently, vari- ous care needs of the older are growing. Hence, the presence of chronic diseases in older people in nursing homes and the relationship between diseases and nutrition should be determined. According to the World Health Organization (WHO), nutrition refers to the intake of nutrients necessary for the body. Regular physical activity and an adequate, well-balanced diet are the cornerstones of health. Malnutrition refers to deficiencies, excesses or imbalances in a person's energy and/or nutritional intake; it may include underweight or obesity. ${ }^{1}$ Malnutrition leads to decreased immunity, increased susceptibility to diseases and physical and mental development imbalances.

In addition to being a biological process that develops beyond human control, ageing varies in each individual, depending on the speed of physiological losses and quality of life. According to Aging is described as the irreversible structural and functional changes of cells, tissues, organs and systems, starting from the molecular level of the organism., ${ }^{2,3}$ Gorman (1999) noted that aging is the point at which active participation in life is no longer possible because of physical deterioration. ${ }^{4}$

According to the WHO, people aged 65 years and over are considered to be older. According to the Turkey Statistical Institute data, the population aged 65 years and older in Turkey increased from $5.7 \%$ in 2000 to $7.7 \%$ in 2013 and to $8.5 \%$ in 2018 . In 2050 , 1 out of 5 individuals worldwide is estimated to be over 60 years old. ${ }^{5}$ Aging changes the person not only physiologically, but also psychologically and sociologically. In a study of the literature, biological changes and decreased physical activity cause chronic nutritional problems and loss of strength. ${ }^{6}$ Wells et al. (2006) and Saka (2010) reported that the individual's nutritional status is affected by factors such as physiological changes that occur with aging, different diseases, dental and oral health problems, economic difficulties, inability to shop alone and difficulties in preparing and eating food. The mortality rate increased by $9 \%$ to $38 \%$ at 1 2.5 years after the onset of weight loss, irrespective of its cause. ${ }^{7,8}$

Older people can suffer from multiple diseases simultaneously. While unbalanced nutrition triggers both acute and chronic diseases, it also indirectly accelerates the aging process. ${ }^{9}$ Malnutrition in the older is associated with increased mortality, increased susceptibility to infections, and decreased quality of life. ${ }^{10}$ Adequate and balanced nutrition is important in terms of protecting and improving health and increasing the length and quality of life.

The aim of the study is to determine the
Correspondence: Melahat Kizil, Izmir University of Economics, Vocational School of Health Services, Izmir, Turkey. E-mail: melahatkizil@gmail.com

Key words: Older; malnutrition; chronic diseases.

Acknowledgments: many thanks to all elders who voluntarily participated in this research.

Contributions: the authors contributed equally,

Conflicts of interest: the authors declare no potential conflict of interest.

Availability of data and materials: as data, a questionnaire study was conducted with the volunteer elders using face to face interview method and these data are kept by the researchers.

Ethics approval and consent to participate: the ethics committee was not necessary. Permission was obtained from the nursing home administration for this study.

Received for publication: 27 February 2020 Revision received: 21 September 2020. Accepted for publication: 14 October 2020.

This work is licensed under a Creative Commons Attribution-NonCommercial 4.0 International License (CC BY-NC 4.0).

${ }^{\circ}$ Copyright: the Author(s), 2020

Licensee PAGEPress, Italy

Geriatric Care 2020; 6:8920

doi:10.4081/gc.2020.8920

relationship between chronic diseases and nutrition in the older adults in a nursing home.

\section{Materials and Methods}

This study was conducted in 2014 and 2019. The participants were older (60 years old or older) who resided at the Izmir Metropolitan Municipality Zubeyde Hanim Nursing Home at the time of the study, agreed to participate and could perform selfcare. In the face-to-face sessions, the Turkish version of Mini Nutritional Assessment TestShort Form $\left(\mathrm{MNA}{ }^{\circledR}-\mathrm{SF}\right)^{11}$ and a 26 -item questionnaire focusing on sociodemographic, socioeconomic and chronic diseases were applied to all participants.

This assessment test aims to screen the nutritional status of the older, to evaluate the risk of malnutrition and to identify people who may benefit from early intervention. Its validity and reliability are proven. It defines 
the person's nutritional status as malnutrition between 0 and 7 points, malnutrition risk between 8 and 11 points and normal nutritional status at 12 points and above.

For data analysis, chi-square test, ANOVA, $t$ test, correlation and regression analysis methods were used as descriptive statistical applications. Furthermore, $\mathrm{P}<0.05$ was considered significant. The dependent variable of the study is $\mathrm{MNA} \AA-\mathrm{SF} \AA-\mathrm{SF}$, whereas the independent variables are sociodemographic and socioeconomic features, exercise, presence of chronic disease, disability, hospitalization and activity status.

\section{Results}

The study was conducted in 2014 and again in 2019, involving 155 older people aged 60 years and over who were residents at the Izmir Metropolitan Municipality Zubeyde Hanim Nursing Home and could perform self-care. We obtained the following results by average: $\mathrm{MNA}{ }^{\circledR}-\mathrm{SF} \AA-\mathrm{SF}$ score: $11.1 \pm 4.6$, body mass index: $27.36 \pm 4.6$, age: $75.8 \pm 8.3$, height: $164.5 \pm 9.1$ and weight: $73.83 \pm 12.9$.

In the 2014 study, 74 older people vol- untarily participated. They were composed of 41 women $(55.4 \%)$ and 33 men (44.6\%), and $28.4 \%$ and $63 \%$ of the participants aged between 65 and 74 years and 75 and 84 years, respectively.

Moreover, $27 \%$ of the older were illiterate, and $45.9 \%$ were primary school graduates. Widowers accounted for slightly more than half of the study population $(51.4 \%)$, whereas only few remained married $(9.5 \%)$. Meanwhile, $32.4 \%$ had no children. In addition, majority $(70.3 \%)$ were receiving social security payments, while $33.8 \%$ had no income (Table 1).

Table 1. Summarizes the sociodemographic and socioeconomic findings of the research group.

\begin{tabular}{|c|c|c|c|c|}
\hline Properties & Number of subjects $(n=74) 2014$ & Rate (\%) & Number of subjects $(n=77) 2019$ & Rate(\%) \\
\hline \multicolumn{5}{|l|}{ Age } \\
\hline $60-64$ & - & - & 7 & 9.1 \\
\hline $65-74$ & 21 & 28.4 & 29 & 37.7 \\
\hline $75-84$ & 47 & 63.5 & 27 & 35.1 \\
\hline 85 and more & 6 & 8.1 & 14 & 18.2 \\
\hline \multicolumn{5}{|l|}{ Gender } \\
\hline Male & 33 & 44.6 & 34 & 44.2 \\
\hline Female & 41 & 55.4 & 43 & 55.8 \\
\hline \multicolumn{5}{|l|}{ Education status } \\
\hline Illiterate & 20 & 27 & 11 & 14.3 \\
\hline Literate & 10 & 13.5 & 6 & 7.8 \\
\hline Primary School & 34 & 45.9 & 40 & 51.9 \\
\hline High-School & $-\frac{1}{2}$ & 10.8 & 15 & 19.5 \\
\hline Graduate School/University & 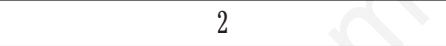 & 2.7 & 4 & 5.2 \\
\hline \multicolumn{5}{|l|}{ Occupation } \\
\hline Worker & 9 & 12.2 & 11 & 14.3 \\
\hline Officers & 11 & 14.9 & 5 & 6.5 \\
\hline Self-employment & 14 & 18.9 & 20 & 26.0 \\
\hline Farmer & 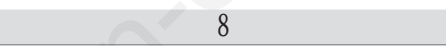 & 10.8 & 2 & 2.6 \\
\hline Housewife & 29 & 39.2 & 24 & 31.2 \\
\hline Other & 3 & 4.1 & 15 & 19.5 \\
\hline \multicolumn{5}{|l|}{ Marital status } \\
\hline Married & 7 & 9.5 & 12 & 15.6 \\
\hline Single & 14 & 18.9 & 22 & 28.6 \\
\hline Widow & 38 & 51.4 & 36 & 46.8 \\
\hline Divorced & 15 & 20.3 & 7 & 9.1 \\
\hline \multicolumn{5}{|l|}{ Health insurance } \\
\hline Yes & 52 & 70.3 & 56 & 72.7 \\
\hline No & 22 & 29.7 & 21 & 27.3 \\
\hline \multicolumn{5}{|l|}{ Number of children } \\
\hline 0 & 24 & 32.4 & 23 & 29.9 \\
\hline 1 & 8 & 1.8 & 2 & 2.6 \\
\hline 2 & 16 & 21.6 & 29 & 37.7 \\
\hline 3 & 21 & 28.4 & 13 & 16.9 \\
\hline 4 and more & 5 & 6.8 & 10 & 13.0 \\
\hline \multicolumn{5}{|l|}{ Income } \\
\hline Yes & 49 & 66.2 & 48 & 62.3 \\
\hline No & 25 & 33.8 & 29 & 37.7 \\
\hline
\end{tabular}


In terms of lifestyle, 28.4 smoked cigarettes, $16.2 \%$ drank alcohol, $43.2 \%, 55.4 \%$ had no hobbies, $48.6 \%$ seldom exercised, and $24.3 \%$ exercised every day.

Regarding health status, $13.5 \%$ had a permanent disability; $67.6 \%$ had at least one chronic disease, with high blood pressure, diabetes and heart problems as the most common; high blood pressure $(54 \%)$, heart failure $(25.6 \%)$ and diabetes $(17.6 \%)$ and $63.5 \%$ of the older had previously been hospitalized for some reason (Table 2).

In 2019, 77 older volunteers participated, consisting of 34 women $(55.4 \%)$ and 43 men $(44.6 \%)$, with a mean age of $75.8 \pm 8.3$ years. In particular, $9.1 \%$ aged $60-64$ years, $37.7 \%$ aged $65-74$ years, $35.1 \%$ aged $75-84$ years and $18.2 \%$ aged 85 years and above.

Furthermore, $14.3 \%$ of the older were illiterate, and $51.9 \%$ were primary school graduates. Widowers accounted for slightly less than half of the study population (46.8\%), whereas married ones accounted for $15.6 \%$. Meanwhile, $29.9 \%$ had no children. Moreover, $72.7 \%$ have social security, whereas $37.7 \%$ had no income. The sociodemographic and socioeconomic findings for 2019 are also shown in Table 1.

Regarding lifestyle, $28.6 \%$ of the older smoked, $13 \%$ drank alcohol, $58.4 \%$ did no exercise at all, and $18.2 \%$ had a permanent disability.

In terms of health status, $63.6 \%$ had at least one chronic disease, with high blood pressure $(50.6 \%)$, heart failure $(22.1 \%)$ and diabetes $(19.5 \%)$ as the most common; and $70.1 \%$ had previously been hospitalized for some reason (Table 3).

In $2014,68.9 \%$ of the older had no malnutrition, $23 \%$ had malnutrition risk, and $8.1 \%$ had actual malnutrition. Women and men were significantly different according to the MNA ${ }^{\circledR}-\mathrm{SF}$ scores $(\mathrm{P}<0.05)$. The
MNA®-SF scores positively correlated with the chronic disease scores $(r=0.508$, $\mathrm{P}<0.05$ ).

\section{Discussion and Conclusions}

This study was first applied to 74 older people aged 60 and over who are self-caring, non-demented (because these patients are in the geriatric department of the nursing home), living in İzmir Metropolitan Municipality Zubeyde Hanim Nursing Home. During this period, these older people moved from their nursing home to a new nursing home, whose conditions were much better. We reported the results of the research we did at that time to the nursing home management, but we did not publish it. After 5 years, we re-applied the same study to the same age group to reevaluate

Table 2. Descriptive symptoms/findings of the research group.

\begin{tabular}{|c|c|c|c|c|}
\hline Properties & Number of subjects $(n=74) 2014$ & Rate (\%) & Number of subjects $(n=77) 2019$ & Rate (\%) \\
\hline \multicolumn{5}{|l|}{ Cigarette } \\
\hline Yes & 21 & 28.4 & 22 & 28.6 \\
\hline No & 47 & 63.5 & 55 & 71.4 \\
\hline \multicolumn{5}{|l|}{ Alcohol } \\
\hline Yes & 12 & 16.2 & 10 & 13.0 \\
\hline No & 62 & 83.8 & 67 & 87.0 \\
\hline \multicolumn{5}{|l|}{ Exercise } \\
\hline Yes & 36 & 48.6 & 31 & 40.3 \\
\hline No & $\mathrm{cos}$ & 51.4 & 46 & 59.7 \\
\hline \multicolumn{5}{|l|}{ Presence of illness } \\
\hline Yes & 50 & 67.6 & 49 & 63.6 \\
\hline No & 24 & 32.4 & 28 & 36.4 \\
\hline \multicolumn{5}{|c|}{ Presence of disability } \\
\hline Yes & 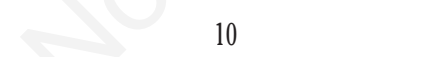 & 13.5 & 14 & 18.2 \\
\hline No & (n) & 83.8 & 63 & 81.8 \\
\hline \multicolumn{5}{|l|}{ Hospitalize } \\
\hline Yes & 47 & 63.5 & 54 & 70.1 \\
\hline No & 27 & 36.5 & 23 & 29.9 \\
\hline \multicolumn{5}{|l|}{ Exercise } \\
\hline $10 \mathrm{~min} /$ day & 8 & 22.2 & 7 & 9.1 \\
\hline $20 \mathrm{~min} /$ day & 12 & 33.3 & 13 & 16.9 \\
\hline $1 \mathrm{day} /$ week & 9 & 25 & 1 & 1.3 \\
\hline 2 days/week (20 min) & 7 & 19.4 & 5 & 6.5 \\
\hline \multicolumn{5}{|l|}{ Chronic diseases } \\
\hline $\mathrm{CAD}$ & 19 & 25.6 & 17 & 22.1 \\
\hline High blood pressure & 40 & 54 & 39 & 50.6 \\
\hline Osteoporosis & 14 & 18.9 & 11 & 14.3 \\
\hline Stroke & 10 & 13.5 & 8 & 10.4 \\
\hline Diabetes & 13 & 17.6 & 15 & 19.5 \\
\hline COPD & 4 & 5.4 & 6 & 7.8 \\
\hline
\end{tabular}

$\mathrm{CAD}$, coronary artery disease; COPD, chronic obstructive pulmonary disease. 
whether there was a change in the elder's status in the new nursing home.

Many problems arise because of the physiological, psychological and social changes caused by aging. Among these problems include nutritional problems and chronic diseases. Aging-related chronic diseases, physiological losses, dental and eating problems and depression can lead to malnutrition, especially in the older. This study found that the nutritional score and the presence of chronic disease were related $(\mathrm{P}<0.05)$.

Social and emotional changes, such as loss of spouse and having to leave home and friends, can cause depression and malnutrition. These changes may affect daily-life skills (such as eating and cooking) or lead to malnutrition (via loss of appetite, not eating) properly. ${ }^{12}$

In the 2014 study, $68.9 \%$ of the older had no malnutrition, $23 \%$ had malnutrition risk, and $8.1 \%$ had malnutrition. In 2019 , $41.6 \%$ had malnutrition risk, and $7.8 \%$ had malnutrition. Although the rate of malnutrition decreased significantly over the years, the risk of malnutrition almost doubled.

In various studies, the rate of malnutrition was higher in the older living in nursing homes than those in their own home. Kaiser et al. (2010) found that the malnutrition rate was $5.8 \%$ in the older living at home, $13.8 \%$ in the nursing home and $38.7 \%$ in hospitalized patients. ${ }^{13}$

Pauly et al. (2007) found that the malnutrition rate was 2 to $38 \%$ and a risk of malnutrition in 37 to $62 \%$ in the nursing home residents. ${ }^{14}$ In Europe and North America, the prevalence of malnutrition is $1-17 \%$ in the older who stay at home, $25-$ $60 \%$ in geriatric care facilities, and $35-65 \%$ in hospitalized older patients. ${ }^{15}$

Ulger et al. (2010) found a $28 \%$ risk of malnutrition in patients admitted to an outpatient clinic. ${ }^{16}$
Velázquez-Alva et al. (2020) found that in a nursing home in Mexico City, the malnutrition risk was $59.9 \%$, whereas malnutrition was $21.1 \% .{ }^{17}$ Malnutrition changes the course of chronic diseases, worsening the condition of patients. ${ }^{18,19}$

In the present study, the presence of chronic disease was $67.6 \%$ and $63.6 \%$ for 2014 and 2019, respectively. Common chronic diseases were hypertension $(50.6 \%)$, heart failure $(22.1 \%)$ and diabetes (19.5\%). Malnutrition risk increased in both groups (2014-2019) with chronic disease $(\mathrm{P}<0.05)$.

Similar to the findings of the current study, the study of Mitsutake et al. found that at least three chronic diseases were present in $65 \%$ of the participants aged over 75 years, with hypertension and heart failure as the most common. ${ }^{20}$

Meinow et al. found that hypertension and heart failure accounted for $38 \%$ and $18 \%$ of the total population, respectively. ${ }^{21}$

Of note, the number of patients with malnutrition who had chronic diseases in 2019 was only half of that in 2014; in other words, only $50 \%$ of those with malnutrition had chronic diseases in 2019. The number acquired in 2014 was reported to the nursing home; consequently, improvements were made to prevent chronic diseases.

In this study, no differences were found between women and men according to the MNA ${ }^{\circledR}-S F$ scores $(\mathrm{P}>0.05)$, as well as between malnutrition and malnutrition risk, in 2019 .

As a result of physiological regression and multiple drug use in the older, food and fluid intake and eating rates decrease, affecting the social and psychological aspects of nutrition. ${ }^{22}$ Low socioeconomic level, lack of education and lack of social security also affect healthy eating. ${ }^{23}$

In the current study, more than half of the residents of the nursing home had low socioeconomic levels and at the same time, lacked income and social security. Seeman et al. (2008) found in their study that socioeconomic status and lack of education pose various health risks. ${ }^{24}$

As supported by many studies, chronic disease is a risk factor for depression. Butcher et al. (2005) found that the symptoms of depression in the older are different from other adults; depression in old age can be seen as a result of other chronic diseases. ${ }^{25}$

Ulger et al. reported that the risk of malnutrition increased because of physical dependence and chronic diseases. ${ }^{16}$ The older are increasingly affected by acute and chronic diseases; therefore, the risk of malnutrition increases. ${ }^{8}$

Exercise benefits nutrition. In the present study, the exercise rate of those with chronic disease was four times higher than those without disease.

In addition, $60 \%-70 \%$ of our participants had previously been hospitalized for some reason. Almost all (83.3\%) participants with malnutrition were hospitalized. Meanwhile, $39.7 \%$ of them performed only daily basic life activities (e.g. bed-to-bed, dressing-undressing, eating, going to the toilet, and taking a bath), while $70.3 \%$ perform both daily basic life activities and auxiliary daily life activities (e.g. using phone, cooking, daily housework, shopping, doing outdoor activities, and travelling out of town). People who cannot perform these activities are more likely to experience malnutrition.

In 2014, according to the MNA ${ }^{\circledR}$-SF scores, women's malnutrition and malnutrition risk were higher than men $(\mathrm{P}<0.05)$. Thus, women are more prone to nutritional deficiencies, and malnutrition is especially common between the ages of 75 and 84 years.

In the study conducted by Basibuyuk et

Table 3. Age and gender distribution of mini nutritional evaluation test-short form and comparison of chronic diseases.

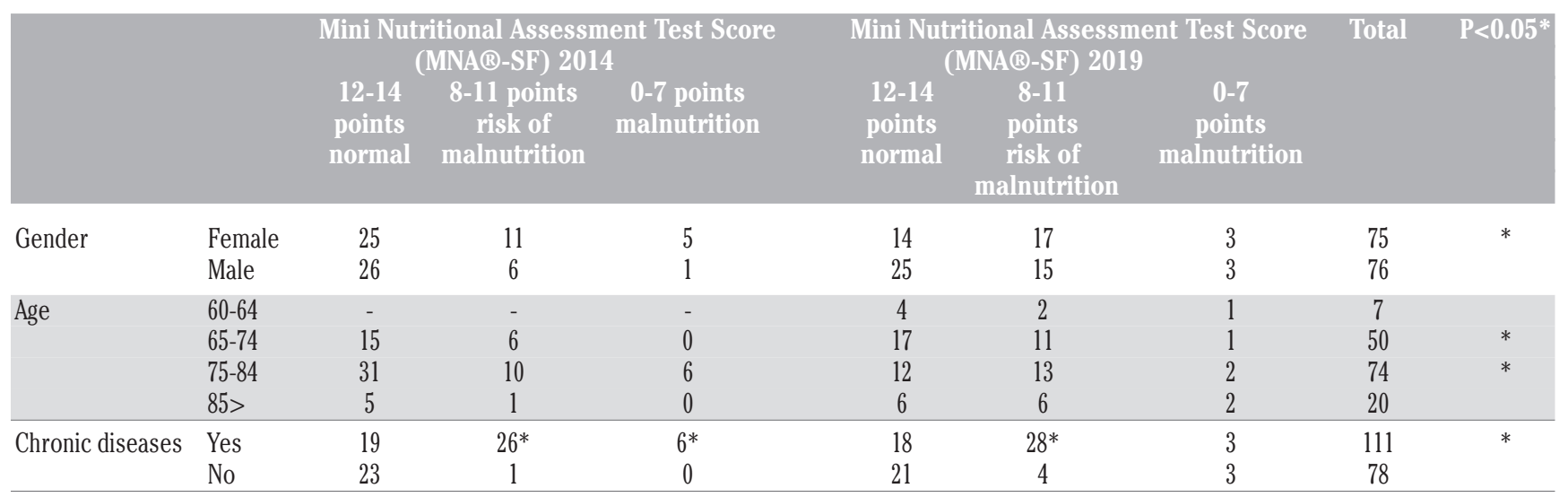

*2014 $(\mathrm{r}=0.508, \mathrm{P}<0.05) 2019(\mathrm{r}=-0.256, \mathrm{P}<0.05)$. Correlation is significant at the 0.05 level (2-tailed). 
$a l$. in nursing homes, malnutrition was more frequently found in women than in men. ${ }^{26}$

The risk of malnutrition and malnutrition in women in 2014 were higher in rate than those in 2019. However, in 2019, no difference was found between malnutrition risk and malnutrition, and between women and men according to the MNA ${ }^{\circledR}-\mathrm{SF}$ scores $(\mathrm{P}>0.05)$.

Malnutrition risk increased in patients with chronic disease in both groups (2014 and 2019) $(\mathrm{P}<0.05)$.

Considering that the older in the nursing home are easily traceable, any problems that may arise can be easily eliminated. Nutritional deficiencies may prevent chronic diseases in the older through special diets, nutrition programs, and exercise programs.

If the older have an adequate and balanced diet, age-related diseases can be prevented or delayed. In older people with high malnutrition risk, reviewing dietary habits, identifying older people with nutritional problems, adjusting their diets with the help of a specialist, providing nutritional support and taking other necessary measures are important factors in improving the quality of life. Informing the older and nursing home staff about healthy nutrition, malnutrition and the precautions they should take is also essential.

The limitations of this study are that the older who remained in the geriatric section of the nursing home and did not want to participate in the research were not included in the research. It is thought that the risk of malnutrition and/or malnutrition may be high in these older who could not be included in the study. Although the healthcare workers in the nursing home where this study was conducted were warned in terms of the results of this study, it is not checked whether the suggestions for improvement made by us are implemented.

In addition, the fact that the nursing home has large venues restricts the relations between the residents of the nursing home and the nursing home staff. The fact that nursing homes are small places may affect the relations between the nursing home residents and nursing home workers more positively.

\section{References}

1. World Health Organization. What is malnutrition?; 2017. Available from: https:/wwwwhoint/features/qa/malnutrition/en/ Accessed: 15 June 2020.

2. Phillip JM, Aifuwa I, Walston J, Wirtz D. The mechanobiology of aging. Annu Rev Biomed Eng 2015;17:113-41.

3. Tosato M, Zamboni V, Ferrini A, Cesari M. The aging process and potential interventions to extend life expectancy. Clin Interv Aging 2007;2:401-12.

4. Gorman M. Development and the rights of older people. In: Randel J, et al. (eds), The ageing and development report: poverty, independence and the world's older people. London, Earthscan Publications, Ltd.; 1999. pp 3-21.

5. Turkish Statistical Institute [Turkstat]. Population and demography. Available from: http://www.tuik.gov.tr Accessed: 15 June 2020.

6. Ahmed T, Haboubi N. Assessment and management of nutrition in older people and its importance to health. Clin Interv Aging 2010;5:207-16.

7. Wells JL, Dumbrell AC. Nutrition and aging: assessment and treatment of compromised nutritional status in frail elderly patients. Clin Interv Aging 2006;1:67-79.

8. Saka B, Kaya O, Ozturk GB, et al. Malnutrition in the elderly and its relationship with other geriatric syndromes. Clin Nutr 2010;29:745-8.

9. Serra-Prat M, Mans E, Palomera E, Clavé P. Gastrointestinal peptides, gastrointestinal motility, and anorexia of aging in frail elderly persons. Neurogastroenterol Motil 2013;25:291-e245.

10. Hickson M. Malnutrition and ageing. Postgrad Med J 2006;82:2-8.

11. Guigoz Y, Vellas B, Garry PJ. Assessing the nutritional status of the elderly: The Mini Nutritional Assessment as part of the geriatric evaluation. Nutr Rev 1996;54:S59-65.

12. Sarikaya D, Halil M, Kuyumcu ME, et al. Mini nutritional assessment test long and short form are valid screening tools in Turkish older adults. Arch Gerontol Geriatr 2015;61:56-60.

13. Kaiser MJ, Bauer JM, Rämsch C, et al. Frequency of malnutrition in older adults: a multinational perspective using the mini nutritional assessment. J Am Geriatr Soc 2010;58:1734-8.

14. Pauly L, Stehle P, Volkert D. Nutritional situation of elderly nursing home residents. Z Gerontol Geriatr 2007;40:3-12.

15. Evans C. Malnutrition in the elderly: a multifactorial failure to thrive. Perman J 2006;9:38-41.
16. Ülger Z, Halil M, Kalan I, et al. Comprehensive assessment of malnutrition risk and related factors in a large group of community-dwelling older adults. Clin Nutr 2010;29:507-11.

17. Velázquez-Alva MC, IrigoyenCamacho ME, Cabrer-Rosales MF, et al. Prevalence of malnutrition and depression in older adults living in nursing homes in Mexico City. Nutrients 2020;12:E2429.

18. Gil-Montoya JA, Ponce G, Sánchez Lara I, et al. Association of the oral health impact profile with malnutrition risk in Spanish elders. Arch Gerontol Geriatr 2013;57:398-402.

19. Johansson L, Sidenvall B, Malmberg B, Christensson L. Who will become malnourished? A prospective study of factors associated with malnutrition in older persons living at home. J Nutr Health Aging 2009;13:855-61.

20. Mitsutake S, Ishizaki T, Teramoto $C$, et al. Patterns of co-occurrence of chronic disease among older adults in Tokyo, Japan. Prev Chronic Dis 2019; 16:E11.

21. Meinow B, Parker MG, Thorslund M. Complex health problems and mortality among the oldest old in Sweden: decreased risk for men between 1992 and 2002. Eur J Ageing 2010;7: 81-90.

22. Rémond D, Shahar DR, Gille D, et al. Understanding the gastrointestinal tract of the elderly to develop dietary solutions that prevent malnutrition. Oncotarget 2015;6:13858-98.

23. Pampel FC, Krueger PM, Denney JT. Socioeconomic disparities in health behaviors. Annu Rev Sociol 2010;36: 349-70.

24. Seeman T, Merkin SS, Crimmins E, et al. Education, income and ethnic differences in cumulative biological risk profiles in a national sample of US adults: NHANES III (1988-1994). Soc Sci Med 2008;66:72-87.

25. Butcher HK, McGonigal-Kenney M. Depression and dispiritedness in later life: a 'gray drizzle of horror' isn't inevitable. Am J Nurs 2005;105:52-61; quiz 61-2.

26. Basibüyük GÖ, Ayremlou P, Aeidlou SNS, Çinar Z, Ay F, Bektas Y, et al. Evaluation of malnutrition among elderly people living in nursing homes by mini nutritional assessment short form (MNA-SF) in Turkey. Maedica (Buchar). 2019 Mar;14(1):38-44. 